\title{
Dynamic mechanical analysis of binary and ternary polymer blends based on nylon copolymer/EPDM rubber and EPM grafted maleic anhydride compatibilizer
}

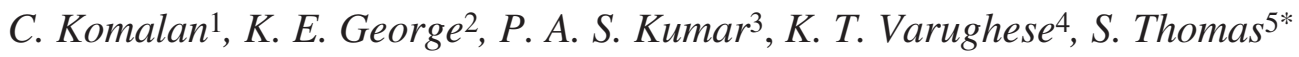 \\ ${ }^{1}$ S.N.M College, Maliankara, Kerala-683516, India \\ ${ }^{2}$ Department of PS\&RT, Cochin University of Science and Technology, Cochin-22, Kerala, India \\ ${ }^{3}$ NIT Calicut P.O, Calicut, Kerala, India \\ ${ }^{4}$ Central Power Research Institute, Bangalore-560080, Karnataka, India \\ ${ }^{5}$ School of Chemical Science, M.G University, Kottayam-686560, Kerala, India
}

Received 30 March 2007; accepted in revised form 17 June 2007

\begin{abstract}
The dynamic mechanical properties such as storage modulus, loss modulus and damping properties of blends of nylon copolymer (PA6,66) with ethylene propylene diene (EPDM) rubber was investigated with special reference to the effect of blend ratio and compatibilisation over a temperature range $-100^{\circ} \mathrm{C}$ to $150^{\circ} \mathrm{C}$ at different frequencies. The effect of change in the composition of the polymer blends on $\tan \delta$ was studied to understand the extent of polymer miscibility and damping characteristics. The loss tangent curve of the blends exhibited two transition peaks, corresponding to the glass transition temperature $\left(T_{g}\right)$ of individual components indicating incompatibility of the blend systems. The morphology of the blends has been examined by using scanning electron microscopy. The Arrhenius relationship was used to calculate the activation energy for the glass transition of the blends. Finally, attempts have been made to compare the experimental data with theoretical models.
\end{abstract}

Keywords: polymer blends and alloys, dynamic mechanical analysis, compatibilisation

\section{Introduction}

Thermoplastic elastomers (TPEs) are being used in a variety of applications because of their desirable mechanical properties and recyclability $[1,2]$. Dynamic mechanical thermal analysis (DMTA) has proved to be an effective tool in the characterisation studies of viscoelastic materials.

Several researchers [3-9] have investigated effects of blend ratio and compatibilisation on the dynamic mechanical properties. Al-Malaika and Kong [10] studied the compatibilisation of functionalised EPR with GMA. Examination of the DMA of the reactive and physically compatibilized blends shows a smaller separation between the glass transition tem- peratures. Rajan et al. [11] have studied the dynamic mechanical properties of PP in the thermoplastic elastomeric state. $\alpha$-relaxation peaks of PEEK and PES and their blends were studied by Nandan et al. [12]. Kumar et al. [13] have studied the dynamic mechanical properties of EPDM-gVOS/LLDPE blends with special reference to the effect of blend ratio. They found that increasing the proportion of LLDPE decreases the $T_{g}$ value of blend and there were increase in $E^{\prime}$ and $E^{\prime \prime}$ due to increase in crystallinity. Karger-Kocsis and Kiss [14] have investigated morphology and dynamic mechanical properties of EPDM/PP blends and PP block polymers. In these blends as the concentra-

*Corresponding author, e-mail: sabut@sancharnet.in

(c) BME-PT and GTE 
tion of EPDM increases, $E^{\prime}$ of the blends decreases. The dynamic mechanical spectrum showed two separate damping peaks and therefore has a twophase morphology indicating that the blend is incompatible. Guo et al. [15] studied the dynamic mechanical properties of PA6/PS blend systems. Gopakumar et al. [16] found that the compatibilisation does not affect the transition temperature of the respective components while several other researchers $[17,18]$ have reported that the incorporation of the compatibilizer leads to obvious shifting of $T_{g}$ 's. These authors are of the opinion that the effect of compatibilizers on the position of $T_{g}$ is a reflection of the extent of compatibilisation. Moly et al. [19] have studied the effect of compatibilisation on the dynamic mechanical properties of LLDPE/EVA blends and found that compatibilisation increased the storage modulus of the system which is due to the fine dispersion of EVA domains in the LLDPE matrix providing an increased interfacial interaction.

In this communication, effects of blend ratio and compatibilisation on the dynamic mechanical properties of nylon copolymer/EPDM blends were investigated. Viscoelastic properties like storage modulus, loss modulus and $\tan \delta$ were investigated as a function of temperature.The dynamic mechanical properties of the new generation of nylon copolymer/EPDM blends are extremely important, as these data are still limited in the literature. The dynamic mechanical properties have been correlated with the morphology of the blends. Attempts have also been made to correlate the experimental viscoelastic data with various theoretical models.

\section{Experimental}

\subsection{Materials}

The raw materials used for this work are as follows. Nylon copolymer (PA6,66) (Tufnyl120) of melting point $148^{\circ} \mathrm{C}$ and density of $1.12 \mathrm{~g} / \mathrm{mol}$, with $\overline{M_{n}}$ 38000 was supplied by SRF Ltd (Madras, India). EPDM (KELTAN 720) with $E / P$ ratio $58 / 35.5$ wt $\%$ and DCPD content $6.5 \mathrm{wt} \%$ with $\bar{M}_{n} 120000$ was obtained from DSM (Netherlands).

The EPM-g-MA with 1 wt $\%$ of MA grafting with $E / P$ ratio 55/45 having density $0.88 \mathrm{~g} / \mathrm{mol}$ (Royaltuf 465) was supplied by Uniroyal Chemical Company, Germany.

\subsection{Blend preparation}

Nylon copolymer (PA6,66) pellets were dried in vacuum oven at $80^{\circ} \mathrm{C}$ for $24 \mathrm{~h}$ before blending. The blends were prepared in a Brabender at a temperature of $180^{\circ} \mathrm{C}$ and a rotor speed of $60 \mathrm{rpm}$. Nylon was first melted for 2 minutes and then EPDM was added and the mixing was continued for 6 more minutes. In the case of compatibilized blends, the compatibilizer EPM-g-MA was mixed with EPDM in a two roll mill at room temperature so as to get EPM-g-MA coated EPDM. Nylon is fed into the preheated Brabender at $180^{\circ} \mathrm{C}$ and melted for 2 minutes. Then EPM-g-MA coated EPDM is added and melting is continued for 6 more minutes (Total mixing time fixed was 8 minutes). Test samples were prepared by compression molding in a hydraulic press at $180^{\circ} \mathrm{C}$. The volumetric proportion of 70/30 nylon/EPDM blends were prepared with compatibilizer concentrations of $0,1,2.5,5$, $10 \mathrm{wt} \%$ based on the minor phase. Test specimens are compression moulded into $2 \mathrm{~mm}$ thick sheets at $180^{\circ} \mathrm{C}$ for 3 minutes in an electrically heated hydraulic press at a pressure of $10 \mathrm{MPa}$.

\subsection{Designation of the blends}

The blends were designated as follows. $N_{0}$ means EPDM and $N_{100}$ means nylon copolymer. $N_{70}$ means a blend of 70 parts of nylon and 30 parts of EPDM. The binary blends were designated as $N_{0}$, $N_{30}, N_{50}, N_{70}$ and $N_{100}$ where the subscripts denote the weight percentage of nylon in the blend. The EPM-g-MA compatibilized $\mathrm{N}_{70}$ blends were designated as $N_{70 x}$, where $x$ denotes the weight percentage of compatibilizer in the blend. Various blends studied with their compositions are summarized in Table 1.

Table 1. Compositions and codes of the samples used

\begin{tabular}{|l|c|c|c|c|c|c|}
\hline \multirow{2}{*}{ System } & \multicolumn{2}{|c|}{ PA6,66 } & \multicolumn{2}{c|}{ EPDM } & \multicolumn{2}{c|}{ EPM-g-MA } \\
\cline { 2 - 7 } & {$[\mathbf{w t} \%]$} & {$[\mathbf{v o l \% ]}$} & {$[\mathbf{w t} \%]$} & {$[\mathbf{v o l \% ]}$} & {$[\mathbf{w t \% ]}$} & [vol\%] \\
\hline$N_{0}$ & - & - & 100 & 100 & - & - \\
\hline$N_{30}$ & 30 & 27.6 & 70 & 72.4 & - & - \\
\hline$N_{50}$ & 50 & 50 & 50 & 50 & - & - \\
\hline$N_{70}$ & 70 & 71.4 & 30 & 30.6 & - & - \\
\hline$N_{100}$ & 100 & 100 & - & - & - & - \\
\hline$N_{701}$ & 70 & 71.4 & 29 & 29.6 & 1 & 0.3 \\
\hline$N_{702.5}$ & 70 & 71.4 & 27.5 & 28.1 & 2.5 & 0.7 \\
\hline$N_{705}$ & 70 & 71.4 & 25 & 25.5 & 5 & 1.3 \\
\hline$N_{7010}$ & 70 & 71.4 & 20 & 20.4 & 10 & 2.0 \\
\hline
\end{tabular}

$N$ - nylon copolymer, $N_{0}$ - ethylene propylene diene rubber 


\subsection{Measurement of dynamic mechanical properties}

The dynamic mechanical properties of nylon/ EPDM blends were determined using Dynamic Mechanical Thermal Analyzer (DMTA; Model2980, supplied by TA Instrument (USA). The shape of test sample is a rectangular strip of $40 \times 12 \times 2 \mathrm{~mm}^{3}$. The dual cantilever mode of deformation was used under the test temperature range from -100 to $150^{\circ} \mathrm{C}$ with a heating rate of $2^{\circ} \mathrm{C} / \mathrm{min}$ under liquid nitrogen flow. Storage modulus $\left(E^{\prime}\right)$ loss modulus $\left(E^{\prime \prime}\right)$ and loss tangent $(\tan \delta)$ of each sample were recorded in multi-frequency mode at $0.1,1,10 \mathrm{~Hz}$.

\subsection{Morphology}

The morphology of the freeze-fractured cross-sections was examined using a scanning electron microscope JEOL JSM-820. Observations were made from etched samples. From $N_{70}$ and $N_{50}$ blends EPDM phase was extracted using xylene vapours. From $N_{30}$ blend, nylon phase is extracted using formic acid. The samples were dried in an air oven at $120^{\circ} \mathrm{C}$ for $24 \mathrm{~h}$ and preserved in a desiccator. The solvent extracted samples were sputter coated with gold $\mathrm{Au}$ ) and SEM observations were made.

\section{Results and discussions}

\subsection{Effect of blend ratio (uncompatibilized blends)}

Dynamic mechanical analysis helps to study polymer/polymer miscibility in polymer blends and also measure the glass transition temperatures $\left(T_{g}\right)$ of polymers. Moreover, we can obtain an idea about the storage (dynamic) modulus, loss modulus and damping behaviour (internal friction). The results of dynamic mechanical analysis add information about the behaviour of the blends and phase morphology. The effects of temperature and blend ratio on the storage modulus $\left(E^{\prime}\right)$ of the samples at a frequency of $10 \mathrm{~Hz}$ are given in the Figure 1. The value of storage modulus, $E^{\prime}$ signifies the stiffness of the material. All the curves show three distinct regions: a glassy high modulus region where the segmental mobility is restricted, a transition zone where a substantial decrease in the $E^{\prime}$ values with increase of temperature and a rubbery region (the

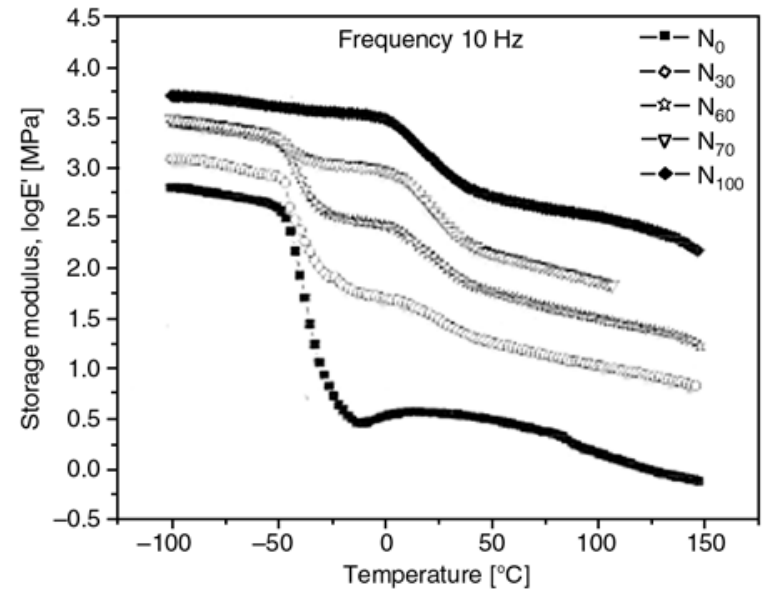

Figure 1. Storage mudulus $\left(E^{\prime}\right)$ curves as function of temperature for nylon, EPDM and physical blend of nylon/EPDM

flow region) where a drastic decay in the modulus with temperature. The storage modulus curve of $\operatorname{EPDM}\left(N_{0}\right)$ shows a typical behaviour of an unvulcanized elastomer. EPDM shows a high modulus below its $T_{g}$ followed by a drastic drop in its magnitude around $-52^{\circ} \mathrm{C}$. This drastic decrease in modulus with temperature around $-52^{\circ} \mathrm{C}$ indicates distinct transition from glassy to rubbery state. At any fixed rate of deformation, the temperature at which $E^{\prime}$ starts to decrease rapidly corresponds to the glass transition temperature. But in the case of nylon, changes in the storage modulus are less severe around the glass transition zone because of its semi-crystalline nature. In the semi-crystalline materials like nylon, the crystalline chains are arranged in a regular order, and it will remain intact until the temperature reaches the melting point $\left(T_{m}\right)$. Only the amorphous part undergoes segmental motion. So, in the case of nylon, the storage modulus decreases to a smaller extent than EPDM does in the transition.

It may be noted that nylon has the maximum and EPDM has the minimum $E^{\prime}$ values. The $E^{\prime}$ values of the blends are found to be intermediate between those of pure components depending on the proportion of EPDM. At very low temperature, modulus of the blends is high. The blends show transition and plateau region corresponding to EPDM and nylon. The storage modulus decreased with increase in temperature and finally levels off at high temperature. It is seen from figure1 that the value of storage modulus decreases with increase in the concentration of EPDM content, which is more pronounced at high temperatures. On adding more 
EPDM, the crystallinity is reduced. Therefore the modulus of EPDM rich blends decreases much faster at high temperatures. EPDM is having very low modulus in the rubbery plateau. The two-step curves in the figure for the blends are due to twophase morphology indicating immiscibility. The above results are very much in agreement with those of systems based on blends of PPIEPDM studied by Papke and Karger-Kocsis [20]. The change from dispersed phase morphology in $N_{30}$ to co-continuous morphology in $N_{50}$ leads to an increase in modulus. In co-continuous structures the storage modulus-temperature dependence reflects a greater contribution of both components, whereas in dispersed structures, the blend modulus is dominated by the matrix component [21]. The relationship between storage modulus at a given temperature can also determine the region of phase inversion and the existence of co-continuous structures, as shown by Dedecker and Groeninckx [22] for reactively compatibilized PA6/PMMA blends. Variation of loss modulus ( $\left.E^{\prime \prime}\right)$ with temperature of nylon, EPDM and nylon/EPDM blends are given in Figure 2. The loss modulus peak corresponds to the maximum heat dissipation per unit deformation. The glass transition temperature, $T_{g}$ was selected as the peak position of $E$ " when plotted as a function of temperature. From the figure, it is clear that $N_{100}$ shows a peak around $13.5^{\circ} \mathrm{C}$ corresponding to the $T_{g}$ of nylon whereas EPDM $\left(N_{0}\right)$ shows a peak around $-44^{\circ} \mathrm{C}$. Another important observation that can be made from the figures is that nylon exhibits a strong $\beta$-relaxation around $-57^{\circ} \mathrm{C}$. However two distinct peaks each exactly corresponding to the glass transition temperatures of nylon and EPDM

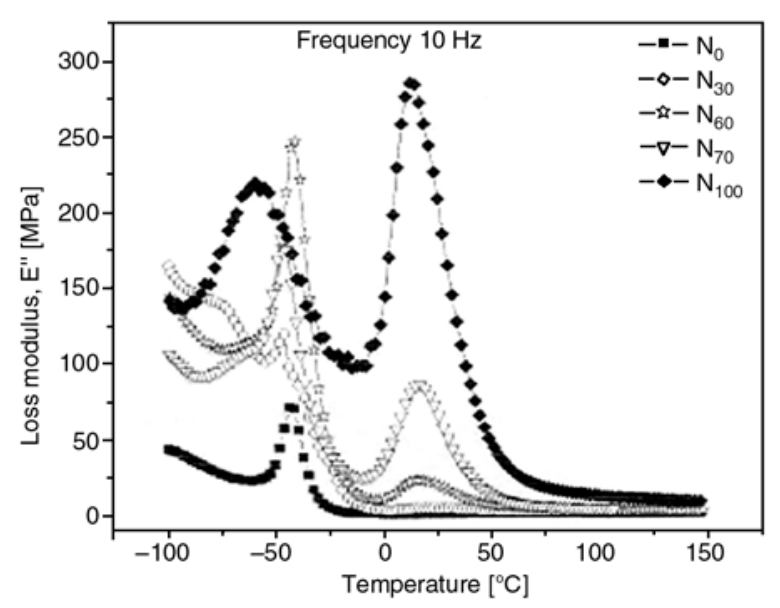

Figure 2. Loss modulus $\left(E^{\prime \prime}\right)$ curves as function of temperature for nylon, EPDM and nylon/EPDM blend can be observed in all the blends indicating the incompatibility and immiscibility between the phases. The loss modulus increases with increase in EPDM content. Various researchers [20, 22, 23] used dynamical mechanical investigation to predict the miscibility of polymeric systems. Generally for incompatible system, the tan $\delta$ versus temperature curve shows two damping peaks corresponding to the glass transition temperatures of individual polymers [20]. When blend components are compatible, a single peak is found for the combined processes [23]. Broadening of the transition occurs in the case of partially compatible systems. Shift in the $T_{g}$ to higher or lower temperatures as a function of composition also indicates the partial miscibility. Figure 3 shows the variation of loss tangent $(\tan \delta)$ with temperature for the pure components and nylon/ EPDM blends. The main relaxation processes in the amorphous region for the nylon and EPDM phases in the blends can be detected from the damping curves presented in Figure 3. As the temperature increases, damping goes through a maximum near $T_{g}$ in the transition region, and then a minimum in the rubbery region. At $T_{g}$, micro-Brownian motion of molecular segments begins where short range diffusion can take place. The damping is low below $T_{g}$ because thermal energy is insufficient to cause rotational and transnational motions of the segments [24]. As a result of this, the chain segments are frozen in. So, below $T_{g}$, the molecular slip resulting in viscous flow is low. Above $T_{g}$ also the damping is low because molecular segments are very free to move about and there is little resistance for their flow. Hence, when the segments are either frozen in or are free to move, damping is low. In the

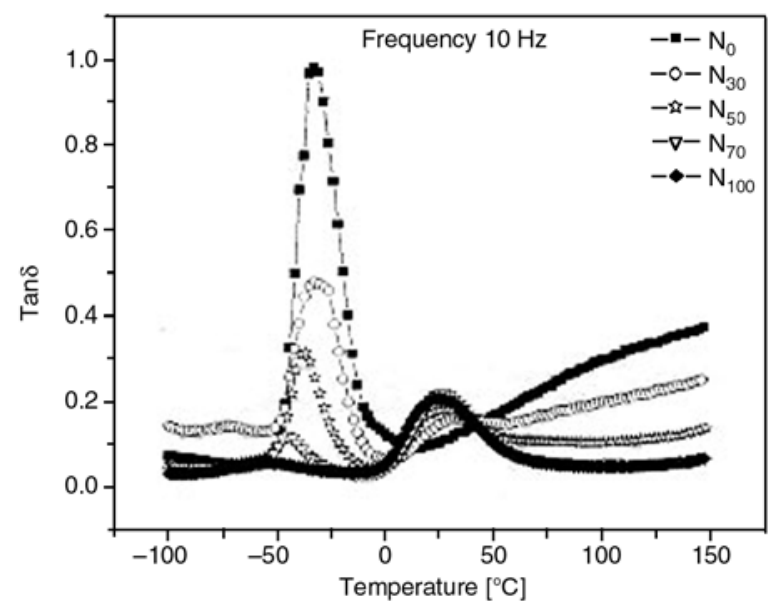

Figure 3. Tan $\delta$ curves as function of temperature for nylon, EPDM and 1 blends nylon/EPDM 
transition region a part of the segments are free to move about and the remainder are not so free. A frozen segment stores energy through deformation and it ultimately releases it as viscous energy when it becomes free to move. The tan $\delta$ curve of EPDM shows a peak at $-32^{\circ} \mathrm{C}$ due to the $\alpha$-transition arising from the segmental motion. This $\alpha$-transition corresponds to the glass transition temperature $\left(T_{g}\right)$ of EPDM. Nylon shows the glass transition temperature at $26^{\circ} \mathrm{C}$. Another important observation that can be made from the Figures 2, 3 is that nylon exhibits a strong $\beta$-relaxation [25] around $-55^{\circ} \mathrm{C}$. It is believed that the $\beta$ damping peak is due to the carbonyl group of nylon forming hydrogen bonds [26]. The temperature of this peak is influenced by nylon moisture content. Some researchers related this secondary transition to movements involving carbonyl groups, which have formed hydrogen bonds with absorbed water [27]. The absence of the $\beta$-relaxation peaks in the blends indicates that addition of EPDM into nylon decreased the water uptake property of nylon as discussed else where. EPDM has higher damping than nylon because of its rubbery nature and the flexible rubber chains respond rapidly towards a cyclic loading. Since the rubber is uncrosslinked, the uncoiling and recoiling process on the application and removal of the stress makes more permanent deformation and thereby registering the highest loss tangent $\left(\tan \delta_{\max }\right)$ values. As can be seen from the figures, all the blend compositions show two distinct and clearly separate tan $\delta$ peaks corresponding to the $T_{g}$ 's of nylon and EPDM indicating that the blends are incompatible. The $T_{g}$ values obtained from the loss modulus

Table 2. $T_{g}$ values of various nylon/EPDM blens $(10 \mathrm{~Hz})$

\begin{tabular}{|l|c|c|c|c|}
\hline \multirow{3}{*}{ Sample } & \multicolumn{3}{|c|}{$\left.\mathbf{T}_{\mathbf{g}}{ }^{\circ}{ }^{\circ} \mathbf{C}\right]$ with respect to } \\
\cline { 2 - 5 } & \multicolumn{2}{|c|}{ EPDM } & \multicolumn{2}{c|}{ Nylon } \\
\cline { 2 - 5 } & $\begin{array}{c}\text { From } \\
\tan \boldsymbol{\delta}_{\text {max }}\end{array}$ & $\begin{array}{c}\text { From } \\
\mathbf{E}^{\prime \prime}\end{array}$ & $\begin{array}{c}\text { From } \\
\tan \boldsymbol{\delta}_{\max }\end{array}$ & $\begin{array}{c}\text { From } \\
\mathbf{E}^{\prime \prime}\end{array}$ \\
\hline$N_{0}$ & -32 & -42 & - & - \\
\hline$N_{30}$ & -31 & -46 & 31 & 17 \\
\hline$N_{50}$ & -37 & -41 & 27 & 17 \\
\hline$N_{70}$ & -44 & -46 & 26 & 16.7 \\
\hline$N_{100}$ & - & - & 26 & 13.5 \\
\hline
\end{tabular}

curve and $\tan \delta$ curves are given in Table 2. As usual, the $T_{g}$ values obtained from $E$ " curves are lower than those from tan $\delta$ curves. The $T_{g}$ values taken from the $\tan \delta$ peaks of virgin polymers and blends at different frequencies are given in Table 3 . In all cases the $T_{g}$ values increase with the frequency. As the mechanical frequency is increased the position of the glass-rubber transition moves to a higher temperature because the polymer chains need more energy to respond to the shorter time scale stresses imposed at higher frequencies. The shift in the $T_{g}$ values upon the addition of the EPDM especially at higher concentrations of EPDM may be due to enhanced chain mobility of nylon due to the plasticizing action of the flexible EPDM phase. The EPDM has the highest damping. It is accepted that higher the $\tan \delta_{\max }$ the greater the mechanical losses. These losses are related to high energy input required for the motion of the molecular chains of the polymer as the transition is being approached [28]. The results also suggested that increasing the rubber content caused an increase of elastic behaviour. A small hump in the $\tan \delta$ peak at lower temperature $\left(-73^{\circ} \mathrm{C}\right)$ of $N_{30}$ may be due to motion of the side chain and imperfection.

The damping behaviour of the blends increases with an increase in the concentration of EPDM rubber. The variation of $\tan \delta_{\max }$ of blend as a function

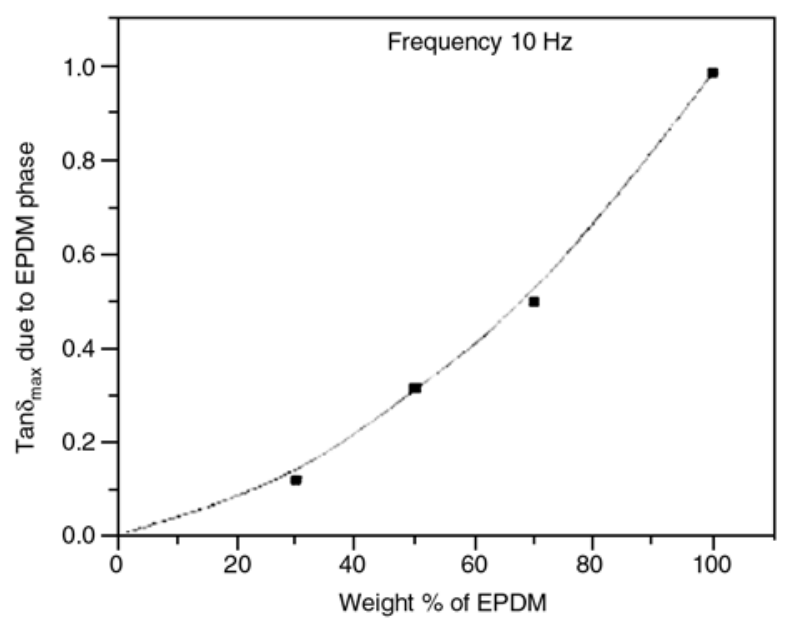

Figure 4. Variation of $\tan \delta$ of nylon, EPDM and nylon/EPDM blends with temperature

Table 3. $T_{g}\left[{ }^{\circ} \mathrm{C}\right]$ values of various nylon/EPDM blends at various frequencies obtained

\begin{tabular}{|c|c|c|c|c|c|c|c|c|}
\hline \multirow{2}{*}{$\begin{array}{c}\text { Frequency } \\
{\left[\begin{array}{l}\mathrm{Hz}]\end{array}\right.}\end{array}$} & \multirow[b]{2}{*}{$\mathbf{N}_{0}$} & \multicolumn{2}{|c|}{$\mathbf{N}_{30}$} & \multicolumn{2}{|c|}{$\mathbf{N}_{50}$} & \multicolumn{2}{|c|}{$\mathbf{N}_{70}$} & \multirow[b]{2}{*}{$\mathbf{N}_{100}$} \\
\hline & & $\begin{array}{l}\text { Due to } \\
\text { EPDM }\end{array}$ & $\begin{array}{c}\text { Due to } \\
\text { nylon }\end{array}$ & $\begin{array}{l}\text { Due to } \\
\text { EPDM }\end{array}$ & $\begin{array}{l}\text { Due to } \\
\text { nylon }\end{array}$ & $\begin{array}{l}\text { Due to } \\
\text { EPDM }\end{array}$ & $\begin{array}{c}\text { Due to } \\
\text { nylon }\end{array}$ & \\
\hline 0.1 & -41 & -45 & 17 & -47 & 20 & -51 & 17 & 13 \\
\hline 1 & -38 & -39 & 20 & -42 & 22 & -47 & 21 & 19 \\
\hline 10 & -32 & -31 & 31 & -37 & 27 & -40 & 26 & 26 \\
\hline
\end{tabular}


of EPDM content measured at $10 \mathrm{~Hz}$ is shown in Figure 4. EPDM shows maximum value of $\tan \delta$ indicating its excellent damping behaviour. In the blends with nylon, the crystalline plastic phase acting as physical crosslinks imposes some restriction towards cyclic loading and the $\tan \delta_{\max }$ decreases with increases in nylon content. The increase in the damping and $\tan \delta_{\max }$ with increase in EPDM content is due to the reduction in the crystalline volume of the system on increasing the concentration of EPDM whose damping is always higher than nylon. The increase in $\tan \delta_{\max }$ of $N_{30}$ (70\% of EPDM) in Figure 4 can be explained by morphological changes. Examination of the morphology of
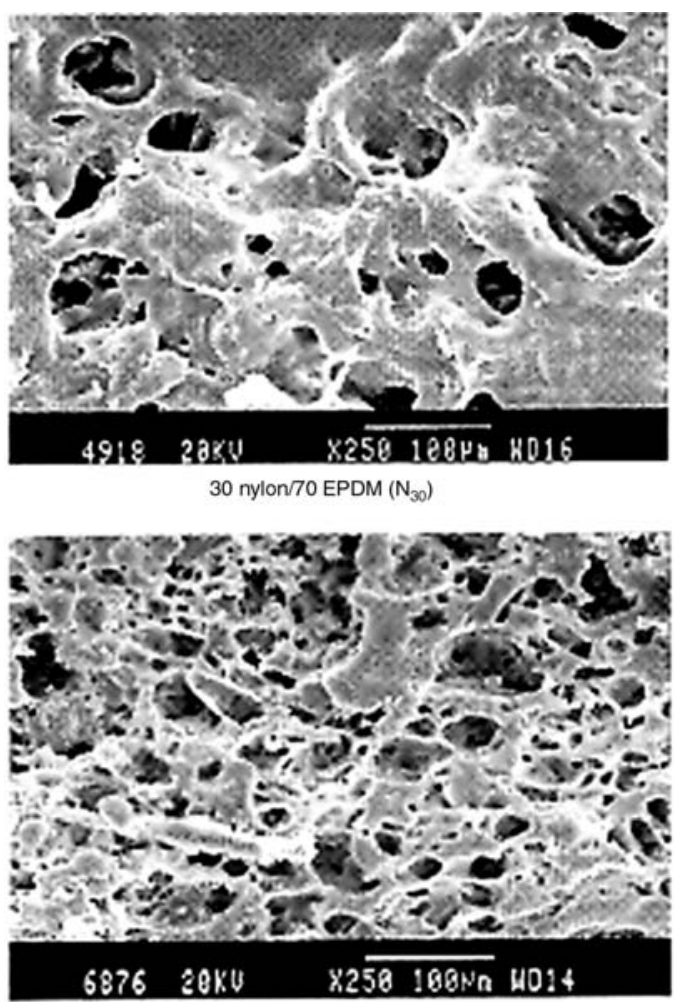

50 nylon/50 EPDM $\left(\mathrm{N}_{50}\right)$

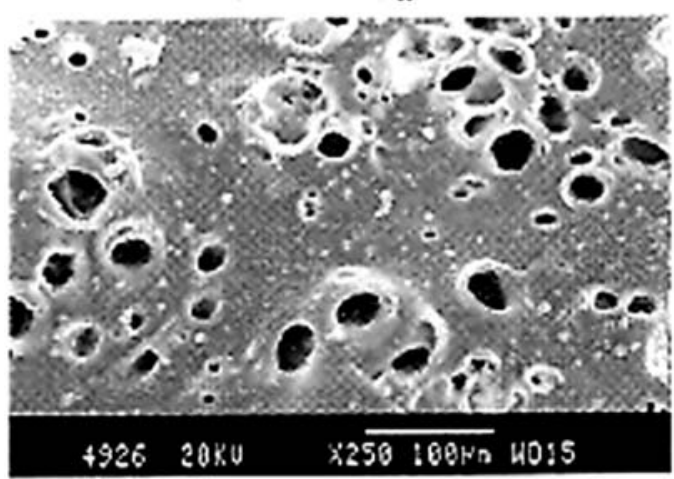

70 nylon/30 EPDM $\left(\mathrm{N}_{70}\right)$

Figure 5. Scanning electron micrograph of nylon copolymer/EPDM blends at a magnification of 250 times the blends by scanning electron microscope (Figure 5) reveals that for blends containing $70 \%$ EPDM, the nylon phase is dispersed as spherical particles (observed as semi-spherical holes after etching by hot xylene to remove the EPDM phase) in the continuous EPDM matrix. In $N_{30}$, the rubber phase has become continuous and its response towards a cyclic loading is more effective and there by exhibiting highest $\tan \delta_{\max }$. In $N_{70}$, nylon is found to form the continuous phase in the blends due to its increased concentration. In this contribution of rubber towards $\tan \delta_{\max }$ is restricted by the crystalline plastic phase. $N_{50}$ blend shows a co-continuous morphology and the rubber particles exist as large domains and their contribution towards $\tan \delta_{\max }$ is increased. SEM micrographs of the blends show a clear two phase morphology with the rubber particles being coarsely dispersed in the continuous nylon phase and having clear and sharp interfacial boundaries which may be attributed to high interfacial tension indicating poor adhesion at phase boundaries, and this is a manifestation of the incompatibility of the polymer components in these blends. It is well known that blends based on immiscible polymer pairs are characterized by great interfacial tension, which makes the dispersion during the blending operation difficult, and contributes to unstable morphology and poor adhesion [29].

The activation energy, $E$ for the glass transition of the blends can be calculated from the Arrhenius equation (1):

$\log f=\log A-2.030 \frac{E}{R T}$

where $f$ is the experimental frequency of transition, $A$, is a constant, $E$ is the activation energy, $R$ is the universal gas constant, $T$ is the temperature corresponding to the maximum of the $\tan \delta$ curve in Kelvin scale [K]. The plots of $\log f$ versus $1 / T$ were constructed and the values of the activation energies were calculated from the slope of the plots. This slope corresponds to the activation energy of the viscous flow that accompanies the glass transition. The Arrhenius plot corresponding to EPDM transition in 70/30 nylon/EPDM blend is given in the Figure 6. Activation energy values are given in the Table 4 . The blends show higher activation energy than the EPDM. Due to the amorphous nature of the EPDM, it is less sensitive to tempera- 


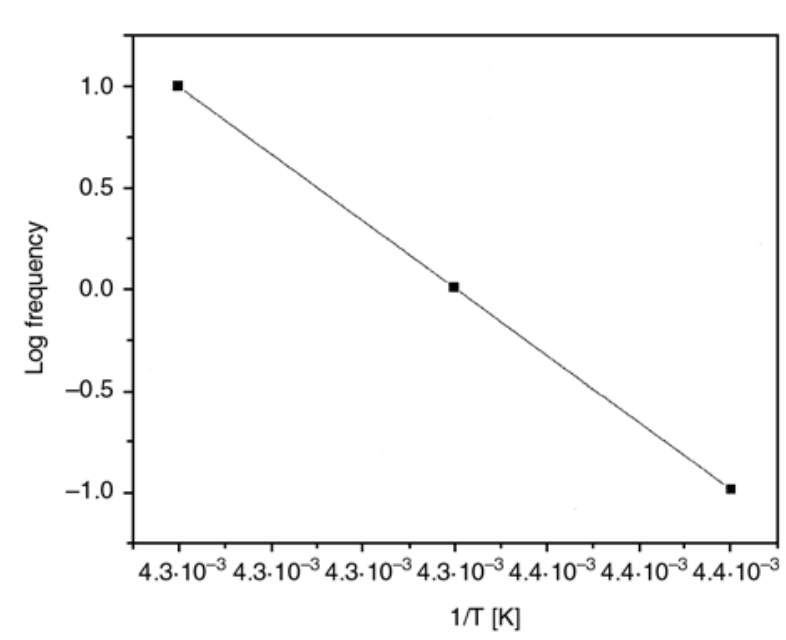

Figure 6. Arrhenious plot corresponding to EPDM transition in 70/30 nylon/EPDM blends

Table 4. Activation energy for the transition of EPDM phase in nylon/EPDM blends

\begin{tabular}{|l|c|}
\hline Sample & $\begin{array}{c}\text { Activation energy }(\boldsymbol{\Delta E})\left[\mathbf{k J} / \mathbf{m o l}^{-\mathbf{1}}\right] \\
\text { for EPDM phase transition }\end{array}$ \\
\hline$N_{70}$ & 423 \\
\hline$N_{50}$ & 261 \\
\hline$N_{30}$ & 189 \\
\hline$N_{0}$ & 51 \\
\hline
\end{tabular}

ture hence the activation energy decreases with increase in EPDM content. The chain flexibility increases with increase in the rubber content. As the flexibility increases, the crystallinity decreases. As a result of this the activation energy decreases.

\subsubsection{Theoretical analysis of storage modulus}

Model studies were carried out to assess the behaviour of the two-phase blend from the component property data. The various composite models such as parallel, series, Coran's and Takayanagi's have been used to predict the viscoelasic behaviour of the binary blends. The upper bound of the storage modulus is given by the rule of mixtures (Equation (2)):

$E_{u}=E_{1} \phi_{1}+E_{2} \phi_{2}$

where $E_{u}$ is the property of the blend and $E_{1}$ and $E_{2}$ are the corresponding properties of the components $\phi_{1}$ and $\phi_{2}$ respectively. and represent the volume fraction of components 1 and 2 respectively. This equation is applicable to the materials in which the components are arranged parallel to the applied stress. The applied stress elongates each component by the same amount. In the lowest lower bound series model, the blend components are arranged in series (Reuss prediction) perpendicular to the direction of the applied force. The equation for the series combination of the components is given by Equation (3):

$\frac{1}{E_{L}}=\frac{\phi_{1}}{E_{1}}+\frac{\phi_{2}}{E_{2}}$

where $E_{L}$ is the moduli of the blend in the series model. For both these models, there is no relation between the morphology and the property.

According to Halpin-Tsai model $[30,31]$, the Equation (4) that relates the morphology of the polymer blend to the properties is:

$\frac{E_{1}}{E}=\frac{1+A_{i} B_{i} \phi_{2}}{1-B_{i} \phi_{2}}$

where

$B_{i}=\frac{\frac{E_{1}}{E_{2}}-1}{\frac{E_{1}}{E_{2}}+A_{i}}$

In the Equation (5) the subscript 1 and 2 refer to the continuous and dispersed phases respectively. The constant $A_{i}$ is determined by the morphology of the system. For elastomer domains, dispersed in a continuous hard matrix, $A_{i}=0.66$ and when the hard material forms the dispersed phase, $A_{i}$ is 1.5 . This model was also useful in determining the properties of polymer blends that contained both continuous and discontinuous phases. This model has also been successfully applied by several researchers to systems [32, 33] of polymer composites.

In Coran's model [34], the mechanical properties are generally in between the upper bound parallel model $\left(E_{U}\right)$ and the lower bound series model $\left(E_{L}\right)$ (Equation (6)):

$E=f\left(E_{U}-E_{L}\right)+E_{L}$

where ' $f$ ' can very between zero and unity. The value of ' $f$ ' is given by Equation (7):

$f=V_{H}^{n}\left(n V_{S}+1\right)$

where $n$ contains the aspects of phase morphology. $V_{H}$ and $V_{S}$ are the volume fractions of hard phase and soft phase respectively. It can be seen from Figure 7 that the experimental data are very close to the Coran's modal with an $n$ value of 2.2. 


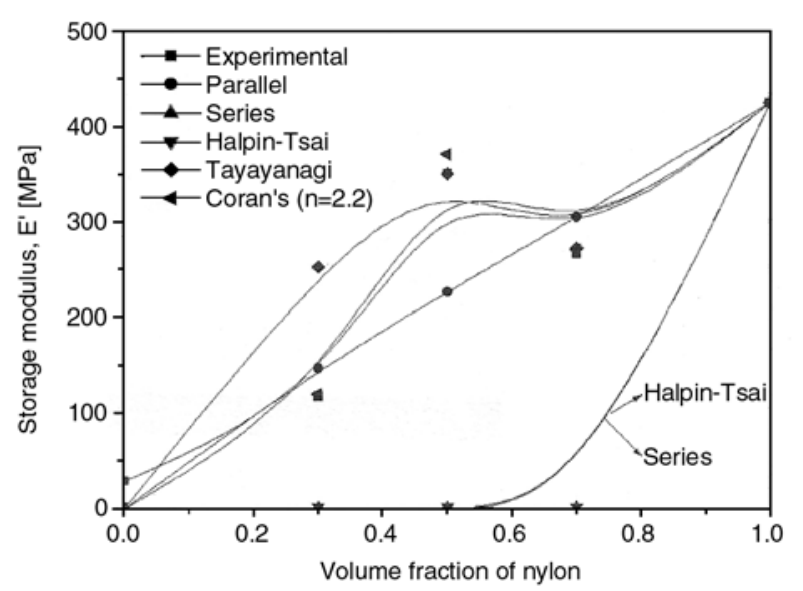

Figure 7. Experimental and theoretical curves of storage modulus of nylon/EPDM blends as a function of volume fraction of nylon at room temperature $\left(28^{\circ} \mathrm{C}\right)$

The viscoelastic behaviour of the heterogeneous polymer blend can be predicted using Takayanagi model [35] in which the concept of percolation is introduced. According to this model (Equation (8)):

$$
E=(1-\lambda) E_{1}+\frac{\lambda}{\frac{1-\phi_{2}}{E_{1}}+\frac{\phi_{2}}{E_{2}}}
$$

where $E_{1}$ is the modulus of the matrix phase, $E_{2}$ is the modulus of the dispersed phase and the values of $\lambda$ and $\phi_{2}$ are related to the degree of series-parallel coupling.

The degree of parallel coupling of the model can be expressed by Equation (9):

$[\%]$ parallel $=\left[\frac{\phi_{2}(1-\lambda)}{1-\phi_{2} \lambda}\right] \cdot 100$

The curves resulting from the different theoretical models and that of the experimental data for the variation of storage modulus at $25^{\circ} \mathrm{C}$ with volume fraction of nylon are given in Figure 7. Coran's model $(n=2)$ fits well with the experimental curve and the Takayanagi model with $45 \%$ parallel coupling agrees to some extent with the experimental curve. The series model is the lowest bound over the entire composition range.

\subsection{Effect of compatibilization}

As discussed in the above section, the nylon copolymer/EPDM blend systems are incompatible. The incorporation of a compatibilizer into an immiscible blend reduces the interfacial energy of the phases, stabilizes the morphology against coalescence and improves the interfacial adhesion. As a result, systems with improved and reproducible properties are obtained.

Dynamic mechanical analysis (DMA) is sensitive to molecular motions and transitions [36] has been chosen as a tool for characterizing blend compatibilisation. The objective of the current work is to use DMA to study the glass transition behaviour of immiscible polymer blends in an effort to characterize blend compatibilisation on the molecular level and to make a correlation between phase morphology and dynamic mechanical properties.

The variation of storage modulus as a function of temperature for 70/30 nylon/EPDM blends compatibilized with different concentrations of EPM-gMA is shown in Figure 8. The $E^{\prime}$ values of compatibilized $\mathrm{N}_{70}$ blends are higher than that of uncompatibilized blend at the same temperature. The addition of EPM-g-MA makes the blend technologically compatible to some extent even though molecular level miscibility cannot be achieved. Even by the addition of $1 \%$ compatibilizer, the storage modulus of the blends shifted towards the lower temperatures, i. e, below the glass transition temperature of nylon. The increase in the modulus upon the addition of the compatibilizer is due to the increase in the interfacial adhesion caused by the emulsifying effect of the copolymer formed by the reaction between EPM-g-MA and nylon. The presence of compatibilizer improves the interfacial adhesion by enhancing the interfacial thickness and thereby facilitating the stress transfer between the components. Thus EPM-g-MA, improved the inter-

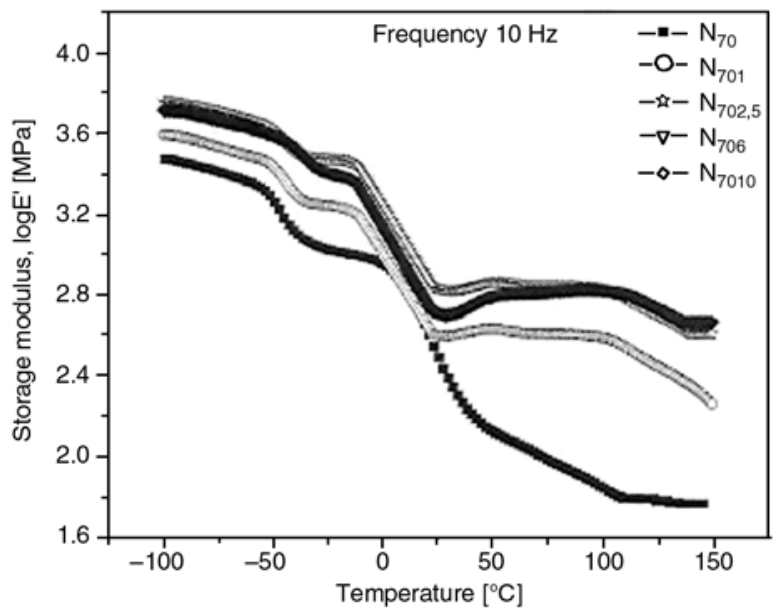

Figure 8. Effect of compatibilisation on the variation of storage modulus as a function of temperature in $N_{70}$ blends 


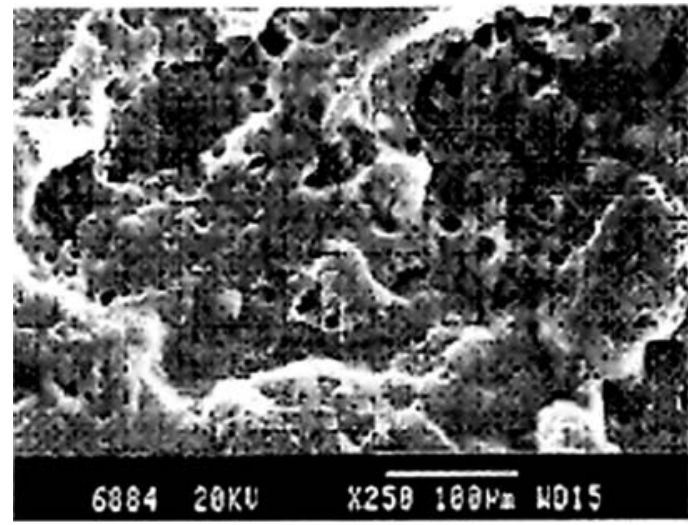

$1 \%$ compatibilizer

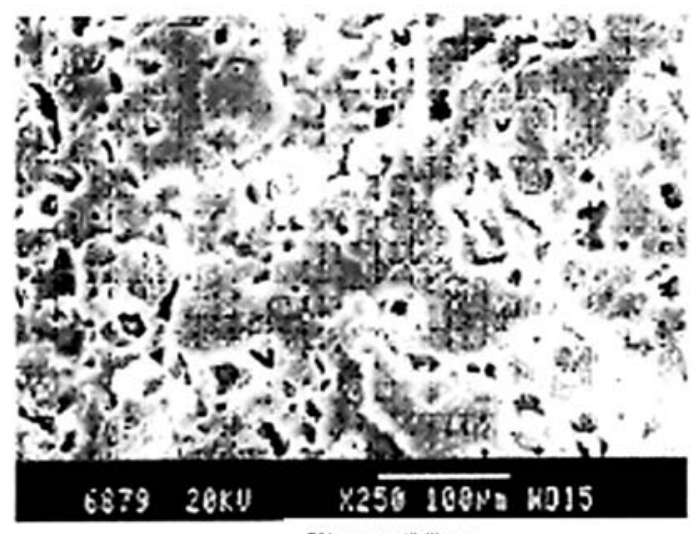

$5 \%$ compatibilizer

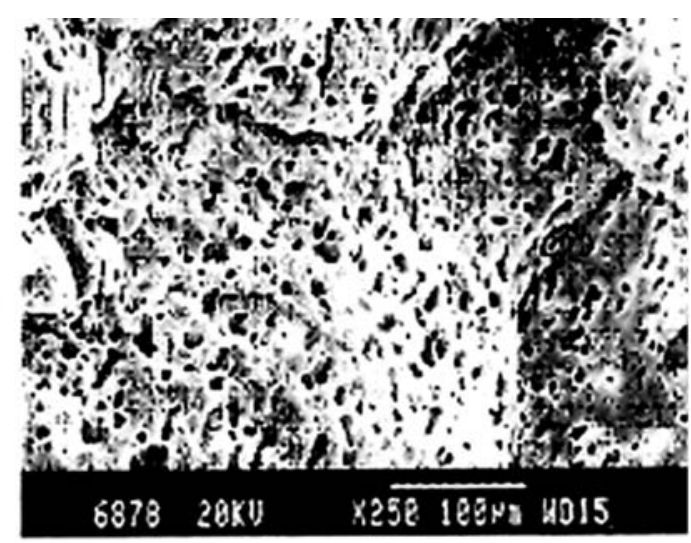

$2.5 \%$ compatibilizer

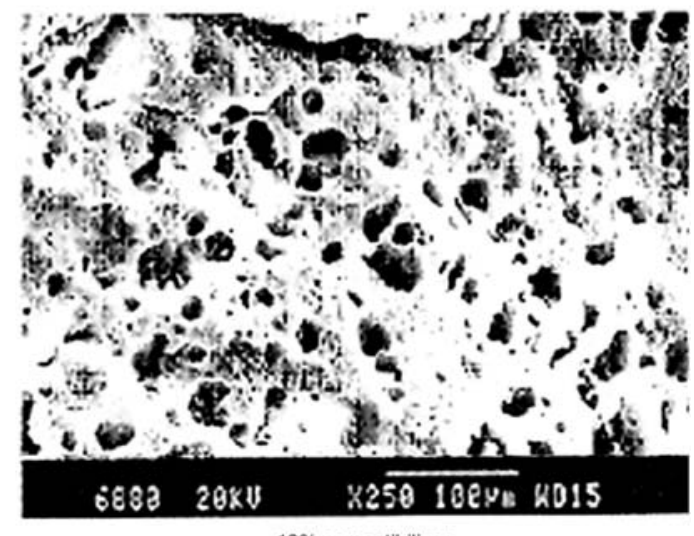

$10 \%$ compatibilizer

Figure 9. Scanning electron micrographs of $N_{70}$ blend containing different levels of EPM-g-MA

facial adhesion, consequently, the storage modulus of the blends enhanced. The increased interfacial interaction is evident from the small and uniform dispersion of EPDM particles upon the addition of EPM-g-MA (Figure 9). A decrease in $E^{\prime}$ by the addition of $10 \mathrm{wt} \%$ EPM-g-MA indicates the formation of micelles in the nylon matrix. At higher loading of the compatibilizer, modulus value decreases due to the formation of agglomerates of the compatibilizer molecule.

Now let us consider the effect of compatibilisation on the $T_{g}$ 's of the blends. Figure 10 depicts the change of loss modulus $\left(E^{\prime \prime}\right)$ as function of temperature for nylon/EPDM blends compatibilized by EPM-g-MA. The $E$ " values of the compatibilized systems are higher than those of $N_{70}$ uncompatibilized blend. The shift in the $T_{g}$ values of the nylon phase of the compatibilized blends compared to the uncompatibilized blends indicate the strong interaction between the nylon and EPDM as a result of reactive compatibilisation. Thus a shifting of $T_{g}$ values of the components is taken as an indication of miscibility enhancement and therefore can be considered as an evidence for compatibilisation.

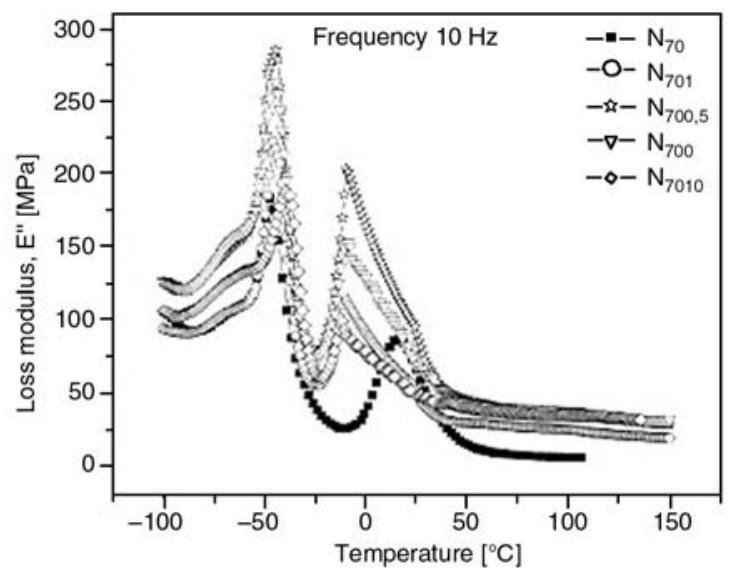

Figure 10. Effect of compatibilisation on the variation of loss modulus as a function of temperature in $N_{70}$ blends

Due to the reaction the mobility of the nylon phase decreases.

There is no change in the $T_{g}$ values of EPDM phase of the compatibilized blends in the loss modulus curve. This is because, at the lower $T_{g}$ in the compatibilized blends, there are two types of constraints imposed on the motions of molecular segments in the vicinity of the interface. One is due to the presence of another phase and other is due to 
the presence of chemical bonds between the two phases. As the blend goes through the lower $T_{g}$, one phase retains its glassiness. The constraints imposed by the glassy phase apparently dominates the presence of chemical bonds between phases. Therefore, no difference is observed when one compares the lower $T_{g}$ behaviour of the compatibilized and uncompatibilized blends. And below $T_{g}$, the molecular mobility is reduced. So the rate of free volume changes with temperature is very small. Therefore, when both blend components are below their respective $T_{g}$, free volume effects are small and $E^{\prime \prime}$ is relatively constant with temperature. Since the compatibilisation reduces interfacial energy and creates a finer dispersion by increasing the interfacial area [37], one can expect an overall volume of the interaction zone to increase when copolymer is added. When the blend goes through the high $T_{g}$, all the molecules are relaxed. In the compatibilized blends the linked segments do not have the degree of mobility as the unlinked segments have, so that the effective number of segments free to completely relaxed has decreased. So there is a shift towards lower $T_{g}$. The $T_{g}$ values obtained (Table 5) from $E^{\prime \prime} v s$. temperature is always less than that obtained from $\tan \delta$ maximum.

DMA has become a classical method for the determination of miscibility because the height and position of the mechanical damping peaks are affected remarkably by miscibility, intermolecular interaction, interface feature and morphology. The variation of $\tan \delta$ as a function of temperature of the compatibilized blends is given in Figure 11. The compatibilized blends also show the presence of two peaks corresponding to the $T_{g}$ 's of nylon and EPDM similar to those of the uncompatibilized

Table 5. Effect of compatibilisation on the $T_{g}$ values of EPDM and nylon in $N_{70}$ blends at $10 \mathrm{~Hz}$

\begin{tabular}{|l|c|c|c|c|}
\hline \multirow{4}{*}{ Blends } & \multicolumn{4}{|c|}{ Glass transition temperature [ ${ }^{\circ}$ C] } \\
\cline { 2 - 5 } & \multicolumn{2}{|c|}{ From E" vs. T curve } & \multicolumn{2}{c|}{ From tan $\delta$ vs. T curve } \\
\cline { 2 - 5 } & $\begin{array}{c}\text { EPDM } \\
\text { phase }\end{array}$ & $\begin{array}{c}\text { Nylon } \\
\text { phase }\end{array}$ & $\begin{array}{c}\text { EPDM } \\
\text { phase }\end{array}$ & $\begin{array}{c}\text { Nylon } \\
\text { phase }\end{array}$ \\
\hline$N_{70}$ & -46 & 16.7 & -40 & 26 \\
\hline $\begin{array}{l}1 \% \\
\text { Compatibiliser }\end{array}$ & -44 & -11 & -41 & 23 \\
\hline $\begin{array}{l}2.5 \% \\
\text { Compatibiliser }\end{array}$ & -44 & -9.3 & -42 & 24 \\
\hline $\begin{array}{l}5 \% \\
\text { Compatibiliser }\end{array}$ & -44 & -9.3 & -42 & 24 \\
\hline $\begin{array}{l}10 \% \\
\text { Compatibiliser }\end{array}$ & -38 & -12 & -36 & 22 \\
\hline
\end{tabular}

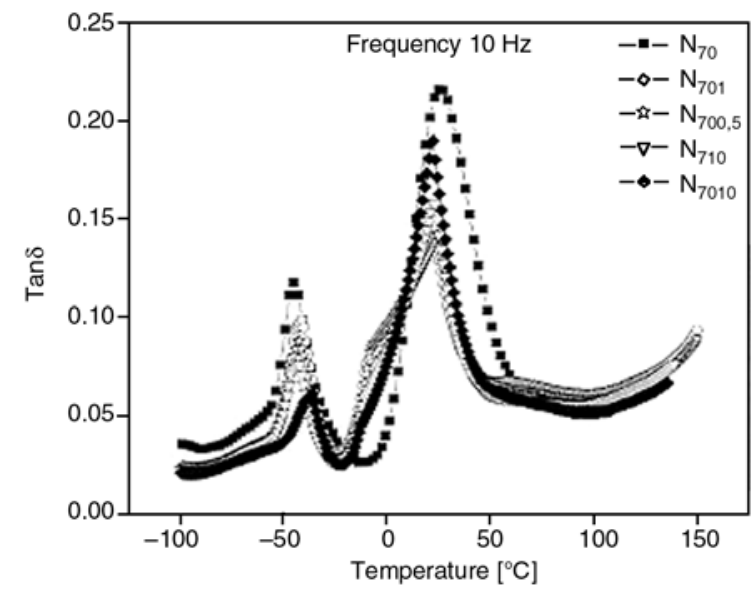

Figure 11. Effect of compatibilisation on the variation of $\tan \delta$ as a function of temperature in $N_{70}$ blends

blends. This indicated that compatibilisation did not alter the degree of miscibility. The broadening of the peaks is an indication of the compatibilisation. The general broadening of the tan $\delta$ peaks is associated with increased molecular mixing [38], which is expected. As the compatibility increases, the interpenetration of the components increases [39]. There is no appreciable shift in the $T_{g}$ towards the average value. This emphasizes that significant miscibility increase does not occur for the compatibilized blends. However, domain boundary mixing [40] or interface mixing [41] have been shown to cause an increased temperature dependence of storage modulus and increased level of loss modulus between $T_{g}$ for compatibilized relative to uncompatibilized blends. From the Figure 11 it is clear that $2.5 \%$ compatibilizer loaded blend shows the highest $\tan \delta$ than other blends in various temperatures. This may be due to the maximum interfacial interaction provided by the compatibilizer. This is evident from the SEM analysis also. Maximum particle size reduction is obtained for $2.5 \%$ of compatibilizer (Figure 9).

We can conclude that both electron microscopy and dynamical mechanical analysis clearly show that the system is still phase separated even in the presence of the compatibilizer and $\tan \delta$ curve also indicates that compatibilizer addition could not make the system completely miscible. This is in agreement with the conclusions made by Paul [42] that if two polymers are far from being miscible, then no copolymer is likely to make a single phase system. In a completely immiscible system, the main role of the copolymer is to act as an interfacial agent. 


\subsection{Degree of entanglement density}

Degree of entanglement of the polymer blends can be obtained from swelling measurements, stressstrain curve and also from dynamic mechanical analysis. We can use the storage modulus data for determining the entanglement density using the Equation (10):

$N=\frac{E^{\prime}}{6 R T}$

where $E^{\prime}$ is the storage modulus obtained from the plateau region of $E^{\prime}$ versus temperature curve, $R$ is the universal gas constant and $T$, is the absolute temperature. A higher degree of entanglement is exhibited by the compatibilized blends when compared to the uncompatibilized blends. This is because by the addition of compatibilizer the entanglement between the homopolymers increases and a better adhesion is achieved as a result of decrease in the interfacial tension. The value for degree entanglement between nylon and EPDM are given in the Table 6. From the morphology studies it is clear that immiscible polymers exhibit a coarse dispersion. By the addition of the compatibilizer the particle size decreased leading to a better adhesion. Oommen et al. [43] reported that the entanglement density increases as a result of compatibilisation. It is interesting to note that, the entanglement density increases up to $2.5 \mathrm{wt} \%$ of compatibilizer concentration followed by a decrease at higher loading. This indicates clearly that the compatibilizer leaves the interface after critical micelle concentration (CMC). Our earlier studies revealed that the minimum amount of compatibilizer (CMC) required to modify the interface is $2.5 \%$ of EPM-g-MA.

Table 6. Entanglement Density of 70/30 nylon/EPDM blends at $10 \mathrm{~Hz}$

\begin{tabular}{|c|c|c|}
\hline $\begin{array}{c}\text { Temperature } \\
{\left[{ }^{\circ} \mathbf{C}\right]}\end{array}$ & $\begin{array}{c}\text { Compatibiliser } \\
{[\mathbf{w t} \%]}\end{array}$ & $\begin{array}{c}\text { Entanglement density } \\
{\left[\mathbf{m o l e s} / \mathbf{m}^{\mathbf{3}}\right]}\end{array}$ \\
\hline \multirow{4}{*}{239} & 0 & 123 \\
\cline { 2 - 3 } & 1 & 152 \\
\cline { 2 - 3 } & 2.5 & 273 \\
\cline { 2 - 3 } & 5 & 251 \\
\cline { 2 - 3 } & 10 & 234 \\
\hline
\end{tabular}

\section{Conclusions}

1. In uncompatibilized blends, nylon shows the maximum and EPDM shows the minimum storage modulus. The storage modulus of blends was found to be intermediate between the pure components.

2. For the uncompatibilized blends, loss modulus and $\tan \delta$ values did not able to give any information about the favourable interactions between nylon and EPDM, as their transition peaks ( $T_{g}$ of nylon $\sim 26^{\circ} \mathrm{C}, T_{g}$ of EPDM $\sim-32^{\circ} \mathrm{C}$ and $\beta$-relaxation of nylon $\sim-57^{\circ} \mathrm{C}$ ) experienced no shift as a function of blend ratio.

3. As the concentration of the EPDM rubber increases the storage modulus decreases and the damping and loss modulus increases.

4. The experimental data of uncompatibilized blends were theoretically modeled and observed that Coran's model $(n=2.2)$ was best suited for the present system and the Takayanagi model with $45 \%$ parallel coupling agrees to some extent.

5. The addition of EPM-g-MA as compatibilizer improved the viscoelastic properties indicating improved interaction between the two components in the compatibilized system.

6. A higher degree of entanglement is exhibited by the compatibilized blends when compared to the uncompatibilized blends.

7. Morphologies of the blends have got a profound influence on the dynamic mechanical properties.

\section{References}

[1] Craver C. D., Carraher C.: Applied polymer science$21^{\text {st }}$ century. Elsevier, New York (2000).

[2] Holden G., Legge N. R., Quirk R. Q., Schroeder H. E.: Thermoplastic elastomers. Hanser-Gardner Publications, Cincinnati (1996).

[3] Yang H., Lai M., Liu W., Sun C., Liu J.: Morphology and thermal and mechanical Properties of PBT/HIPS and PBT/HIPS-g-GMA blends. Journal of Applied Polymer Science, 85, 2600-2608 (2002).

[4] John B., Varughese K. T., Oommen Z., Pötschke P., Thomas S.: Dynamic mechanical behavior of highdensity polyethylene/ethylene vinyl acetate copolymer blends: The effects of the blend ratio, reactive compatibilization, and dynamic vulcanization. Journal of Applied Polymer Science, 87, 2083-2099 (2003).

[5] George J.: Compatibilisation of high density polyethylene/nitrile rubber blends. $\mathrm{PhD}$ thesis, Mahatma Gandhi University (2003).

[6] Ramirez-Vargas E. R., Sandoval-Arellano Z., Hernandez-Valdez J. S., Martinez-Colunga J. G., SanchezValdes S.: Compatibility of HDPE/postconsumer HDPE blends using compatibilizing agents. Journal of Applied Polymer Science, 100, 3696-3706 (2006). 
[7] Diaz M. F., Barbosa S. E., Capiati N. J.: Addition compatibilization of PP/PS blends by tailor-made copolymers. Polymer Engineering and Science, 46, 329-336 (2006).

[8] Mirzazadeh H., Katbab A. A.: PP/EPDM-based thermoplastic dynamic vulcanizates with organoclay: morphology, mechanical and viscoelastic properties. Polymers for Advanced Technologyes, 17, 975-980 (2006).

[9] Yang Y-L., Lin Y., Sell C., Hiver J-M., Bai S-L.: Dynamic mechanical properties and morphology of high-density polyethylene/ $\mathrm{CaCO}_{3}$ blends with and without an impact modifier. Journal of Applied Polymer Science, 103, 3907-3914 (2007).

[10] Al-Malaika S., Kong W.: Reactive processing of polymers: effect of in situ compatibilization on characteristics of blends of polyethylene terephthalate andethylene-propylene rubber. Polymer, 46, 209-228 (2005).

[11] Rajan G. S., Vu Y. T., Mark J. E., Myers C. L.: Thermal and mechanical properties of polypropylene in the thermoplastic elastomeric state. European Polymer Journal, 40, 63-71 (2004).

[12] Nandan B., Kandpal L. D., Mathur G. N.: Glass transition behaviour of poly(ether ether ketone)/poly(aryl ether sulphone) blends: dynamic mechanical and dielectric relaxation studies. Polymer, 44, 1267-1279 (2003).

[13] Kumar M. S. C., Alagar M., Prabu A. A.: Studies on dynamic mechanical and mechanical properties of vinyloxyaminosilane grafted ethylene propylene diene terpolymer/linear low density polyethylene (EPDM-gVOS/LLDPE) blends. European Polymer Journal, 39, 805-816 (2003).

[14] Karger-Kocsis J., Kiss L.: Dynamic mechanical properties and morphology of polypropylene block copolymers and polypropylene/elastomer blends. Polymer Engineering and Science, 27, 254-262 (1987).

[15] Guo T-Y., Song M-D., Hao G-J., Zang B-H.: Compatibility and mechanical properties of polyamide-6/ polystyrene/diblock poly(styrene-b-ethylene oxide) copolymer blends. European Polymer Journal, 37, 241-246 (2001).

[16] Gopakumar T. G., Ponrathnum S., Lele A., Rajan C. R., Fradet A.: In situ compatibilization of poly (phenylene sulphide)/wholly aromatic thermotropic liquid crystalline polymer blends by reactive extrusion: morphology, thermal and mechanical properties. Polymer, 40, 357-364 (1999).

[17] Seo Y.: TLCP ternary blends for in situ composites: In situ compatibilizer. Journal of Applied Polymer Science, 70, 1589-1595 (1998).

[18] Tjong S. C., Li R. K. Y., Xie X. L.: Compatibilizing effect of styrene-maleic anhydride copolymer on the properties of polyamide-6/liquid crystalline copolyester composites. Journal of Applied Polymer Science, 77, 1964-1974 (2000).
[19] Moly K. A., Bhagawan S. S., Groeninckx G., Thomas S.: Correlation between the morphology and dynamic mechanical properties of ethylene vinyl acetate/linear low-density polyethylene blends: Effects of the blend ratio and compatibilisation. Journal of Applied Polymer Science, 100, 4526-4538 (2006).

[20] Papke N., Karger-Kocsis J.: Thermoplastic elastomers based on compatibilized poly(ethylene terephthalate) blends: effect of rubber type and dynamic curing. Polymer, 42, 1109-1120 (2001).

[21] Quintens D., Groeninckx G., Guest M., Aerts L.: Mechanical behavior related to the phase morphology of PC/SAN polymer blends. Polymer Engineering and Science, 30, 1474-1483 (1990).

[22] Dedecker K., Groeninckx G.: Reactive compatibilisation of $\mathrm{A} /(\mathrm{B} / \mathrm{C})$ polymer blends. Part 2 . Analysis of the phase inversion region and the co-continuous phase morphology. Polymer, 39, 4993-5000 (1998).

[23] Varughese K. T., Nando G. B., De P. P., De S. K.: Miscible blends from rigid poly (vinyl chloride) and epoxidised NR. Journal of Material Science, 23, 3894-3900 (1988).

[24] Ferry J. D.: Viscoelastic properties of polymers. John Wiley, New York (1980).

[25] Dickie R. A.: Heterogeneous polymer-polymer composites. I. Theory of viscoelastic properties and equivalent mechanical models. Journal of Applied Polymer Science, 17, 45-63 (1973).

[26] Bell J. P., Murayama T.: Relation between dynamic mechanical properties and dye diffusion behavior in acrylic fibers. Journal of Applied Polymer Science, 12, 1795-1799 (1968).

[27] Gadekar R., Kulkarni A., Jog J. P.: Blends of nylon with polyethylene: Effect of compatibilization on mechanical and dynamic mechanical properties. Journal of Applied Polymer Science, 69, 161-168 (1998).

[28] Sombatsompop N.: Dynamic mechanical properties of SBR and EPDM Vulcanisates filled with cryogenically pulverized flexible polyurethane foam particles. Journal of Applied Polymer Science, 74, 1129-1139 (1999).

[29] Hu G-H., Sun Y-J., Lambla M.: Effects of processing parameters on the in situ compatibilization of polypropylene and poly(butylene terephthalate) blends by one-step reactive extrusion. Journal of Applied Polymer Science, 61, 1039-1047 (1996).

[30] Nielsen L. E.: Morphology and the elastic modulus of block polymers and poly blends. Rheologica Acta, 13, 82-92 (1974).

[31] Halpin J. C.: Structure-property relations and reliability concepts. Journal of Composite Materials, 6, 2082031 (1972).

[32] Kalaprasad G., Joseph K., Thomas S., Pavithran C.: Theoritical modelling of tensile properties of short sisal fibre reinforced low density polyethylene composites. Journal of Material Science, 32, 4261-4267 (1997). 
[33] Nair K. C. M., Divan S. M., Thomas S.: Tensile properties of short sisal fiber reinforced polystyrene composites. Journal of Applied Polymer Science, 60, 1483-1497 (1996).

[34] Stephens H. L., Bhowmick A. K.: Handbook of elastomers: New developments and technology Marcel Dekker, New York (1988).

[35] Dickie R. A.: Heterogeneous polymer-polymer composites. I. Theory of viscoelastic properties and equivalent mechanical models. Journal of Applied Polymer Science, 17, 45-763 (1973).

[36] Murayama T.: Dynamic Mechanical analysis of polymer material. Elsevier, New York (1978).

[37] Paul D. R.: Interfacial agents (compactibilizers) for polymer blends. in 'Polymer Blends' (eds.: Paul D. R., Newman S.) Academic Press INC, New York, Vol 2, 35-62 (1978).

[38] Thomas D. A., Sperling C. H.: Interpenetrating polymer networks. in 'Polymer Blends' (eds.: Paul D. R., Newman S.) Academic Press INC, New York, Vol 2, 1-33 (1978).
[39] Wu S.: Interfacial energy, structure and adhesion between polymers. in 'Polymer Blends' (eds.: Paul D. R., Newman S.) Academic Press INC, New York, Vol 1, 243-293 (1978).

[40] Hashimoto T., Tsukahara Y., Tachi K., Kawai H.: Structure and properties of tapered block polymers. 4. 'Domain-boundary mixing' and 'mixing-in-domain' effects on microdomain morphology and linear dynamic mechanical response. Macromolecules, 16, 648-657 (1983).

[41] Feng D., Wilkens G. L., Crivello J. V.: Structure-property behaviour of free radical synthesized polydimethylsiloxane-polystyrene multiblock polymers: 1 . Effect of the siloxane block length. Polymer, 30, 1800-1813 (1989).

[42] Newman S.: Rubber modifications of plastics. in 'Polymer Blends' (eds.: Paul D. R., Newman S.) Academic Press INC, New York, Vol 2, 63-89 (1978).

[43] Oommen Z., Groninckx G., Thomas S.: Dynamic mechanical and thermal properties of physically compatibilized natural rubber/poly (methyl methacrylate) blends by the addition of natural rubber-graft-poly (methyl methacrylate). Journal of Polymer Science Part B: Polymer Physics, 38, 525-536 (2000). 